\title{
Karakteristik Model Divais Fotoluminisen RGB Multilapis Berbasis Polimer Hibrid
}

\author{
Norman Syakir, ${ }^{1}$ Indra Masruri, ${ }^{1}$ Pina Pitriana, ${ }^{2}$ Rahmat Hidayat, ${ }^{2}$ dan Fitrilawati ${ }^{1, *}$ \\ ${ }^{1}$ Departemen Fisika Fakultas Matematika dan Ilmu Pengetahuan Alam, \\ Universitas Padjadjaran Jl. Raya Bandung-Sumedang KM 21Jatinangor, Sumedang 45363 \\ ${ }^{2}$ KK Fisika Magnetik dan Fotonik, Fakultas MIPA, Institut Teknologi Bandung Jl. Ganesha 10, Bandung 40132
}

Intisari

Dalam makalah ini dilaporkan hasil karakterisasi model divais fotoluminisen RGB (Red,Green,Blue) multilapis berbasiskan polimer hibridorganik-anorganik. Bahan divais fotoluminesen terbuat dari polimer hibrid yang di doping kromofor organik. Prekursor polimer hibrid dibuat dengan teknik Sol-gel darimonomer 3(Trimethoxysilyl) propyl methacrylate (TMSPMA). Kromofor dopan terdiri dari Nile Red (R), Coumarine-6 (G) dan Coumarine-1 (B). Model divais fotoluminisensi RGB terdiri dari tiga lapisan yang dibuat lapis per lapis di atas substrat fused silicadengan menggunakan teknik spincoating. Untuk menghasilkan kombinasi warna emisi, telah dibuat tiga macam model divais dengan konfigurasi urutan lapisan R, G dan Byang berbeda. Karakterisasi dilakukan terhadap pola spektrum absorpsi UV-Vis dan spektrum emisi, dan warna cahaya yang diemisikan.Model divais dengan konfigurasi multilapis memperlihatkan spektrum emisi kontinyu dalam rentang 400nm sampai $700 \mathrm{~nm}$ yang bersesuaian dengan rentang panjang gelombang cahaya putih. Ketiga konfigurasi model divais memiliki pola spektrum emisi berbeda yang disebabkan oleh urutan mekanisme absorpi dan emisi antara ketiga lapisan yang berbeda.

\begin{abstract}
We report characteristics of RGB multilayer photoluminescence device models based on inorganic-organic hybrid polymer.The hybrid polymerdoped with organic chromophores were used as a photoluminescence material. Precursor ofhybrid polymer was synthesized from monomer of 3-(Trimethoxysilyl) propyl methacrylate (TMSPMA). The organic chromophores consist of Nile Red (R), Coumarine-6 (G) and Coumarine-1 (B). The multilayer device models consist of three layers of hybrid polymer with certain chromophore color that prepared layer by layer on fused silica substrates using spincoating technique. In order to obtain various emission color, three configuration of RGB chromophores were prepared. The device models then characterized using UV-Vis absorption and emission spectroscopies. The multilayer device models show continue emission on the range of $400 \mathrm{~nm}$ to $700 \mathrm{~nm}$ that related to the range of white light emission. We obtain three different pattern of emission spectra for three different configurations, that caused by different absorption and emission mechanism for different configuration.
\end{abstract}

KATA KUNCI: hybrid polymers, RGB organic chromophores, photoluminesence device http://dx.doi.org/10.12962/

\section{PENDAHULUAN}

Energi listrik merupakan salah satu bentuk energi yang paling banyak dipergunakan dalam kehidupan sehari-hari yang mana tidak kurang dari 30\% konsumsi listrik tersebut dipakai untuk lampu. Jenis lampu yang banyak digunakan adalah lampu pijar, yang sangat boros karena hampir $90 \%$ energi yang dikonsumsi berubah menjadi panas.

Teknologi penghematan energi melalui pengembangan lampu sebagai sumber pencahayaan buatan sudah mencapai tahap yang efisien. Sebagai contoh, lampu fluorosen gas CFL (Cathode Fluorescence Lamp), dapat mengkonversi hampir $70 \%$ energi yang dikonsumsi menjadi energi cahaya. Namun, lampu CFL tersebut masih memiliki kekurangan terhadap ke-

*E-MAIL: fitrilawati@phys.unpad.ac.id sehatan dan lingkungan, karena mengemisikan sinar UV dan masih menggunakan unsur logam berat merkuri. Selain itu, bentuk dari lampu fluorosen gas tidak dapat dalam ukuran besar dan bentuknya tidak datar sehingga pencahayaannya dalam ruang kurang memadai.

Lampu fluoresen padat atau SSL (Solid State Lighting) merupakan salah satu alternatif untuk menggantikan lampu pijar dan lampu fluoresen gas [1]. Penggunaan lampu fluoresen padat, selain penggunaan gas yang berbahaya dapat dihindari juga emisinya kontinyu dalam rentang cahaya tampak. Pemilihan bahan yang tepat, lampu fluoresen padat tersebut diharapkan dapat dibuat dalam bentuk panel lebar dan dapat ditempelkan di mana saja, dengan demikian distribusi pencahayaan dalam ruang dapat menjadi lebih baik dibanding dengan lampu fluoresen biasa. Pada umumnya lampu fluoresen padat dikembangkan dari bahan berbasis fosfor [1],serta semikonduktor seperti AlInGaP [2] dan InGaN [3].

Pada saat ini, teknologi pengembangan lampu yang lebih hemat energi dan ramah lingkungan telah dicapai melalui je- 
nis lampu bahan padat. Sebagai contoh, lampu LED (Light Emitting Device) dapat 50\% lebih hemat dibanding lampu CFL. Namun, program hemat energi dalam produksi tidak dapat dipenuhi lampu LED karena menggunakan bahan inorganik yang cenderung membutuhkan energi besar dalam pengolahannya. Hal inilah yang menjadi landasan pengembangan SSL berbasis bahan polimer organik atau polimer hibrid organik-inorganik. Penggunakan bahan polimer hibrid, diharapkan biaya produksi dapat dikurangi karena dengan menggunakan bahan polimer tersebut, proses pembuatan divaisnya sangat sederhana dan berbiaya murah.

Salah satu pengembangan bahan SSL berbasis polimer yang telah dilaporkan adalah komposit dari polimer polimetil metakrilat (PMMA) dengan bahan fluoresen RGB [4] dan komposit semikonduktor dengan polimer terkonjugasi [5]. Polimer terkonjugasi banyak diteliti sebagai bahan SSL karena bahan tersebut dapat direkayasa strukturnya sehingga dapat menghasilkan emisi putih dengan menggunakan satu jenis bahan saja [6]. Selain itu, dikembangkan juga kombinasi bahan anorganik dan bahan organik yang menggunakan kromofor fluoresen organik untuk bahan untuk lampu fluoresen padat [7]. Penggunaan polimer hibrid diharapkan lebih baik dari polimer biasa karena polimer hibrid memiliki kombinasi dari gugus organik dan gugus anorganik dalam satu rantai sehingga diharapkan dapat memiliki stabilitas termal yang lebih baik.

Dalam makalah ini akan dilaporkan hasil pembuatan model divais fotoluminisen RGB berbasiskan polimer hibrid dengan konfigurasi multilapis dan hasil karakterisasinya.

\section{METODE}

Prekursor polimer hibrid organik-anorganik disintesis dari monomer 3-(Trimethoxysilyl) propyl methacrylate (TMSPMA, Aldrich)dengan menggunakan teknik Sol-gel. Proses sol-gel diawali dengan melarutkan monomer ke dalam etanol, kemudian ke dalam larutan tersebut ditambahkan H2O sambil diaduk menggunakan magnetic stirrer. Kemudian kedalam campuran tersebut ditambahkan katalis $\mathrm{HCl}$ sampai keasamaan $\mathrm{pH}=2$, lalu diaduk pada suhu $60 \mathrm{oC}$ dengan laju pengadukan sekitar $200 \mathrm{rpm}$ hingga terbentuk gel transparan. Langkah selanjutnya adalah purifikasi untuk menghasilkan prekursor polimer hibrid yang relatif murni.

Kromofor RGB yang digunakan adalah Coumarine-6 (3-(2-Benzothiazolyl)-7-(diethylamino) Coumarine, Aldrich), Coumarine-1 (7-Diethylamino-4-methylCoumarine, Aldrich), dan Nile-Red (Nile Blue A Oxazone, Aldrich). Proses doping kromofor RGB pada prekursor polimer hibrid diawali dengan melarutkan masing-masing kromofor dalam kloroform dan melarutkan prekursor dalam kloroform. Selanjutnya, larutan kromofor dengan konsentrasi $0,1 \%$ berat dicampurkan dengan larutan prekursor, lalu diaduk agar terbentuk larutan yang homogen. Larutan yang dihasilkan kemudian disaring dengan mikrofilter ukuran 0,45 $\mathrm{m}$ dan dikentalkan. Sebelum dibuat lapisan tipis, larutan prekursor polimer hibrid yang mengandung kromofor dicampur dengan fotoinisiator Irgacure-819 (Ciba Speciality Chemical Inc.) dengan konsentrasi $0,5 \%$ be-

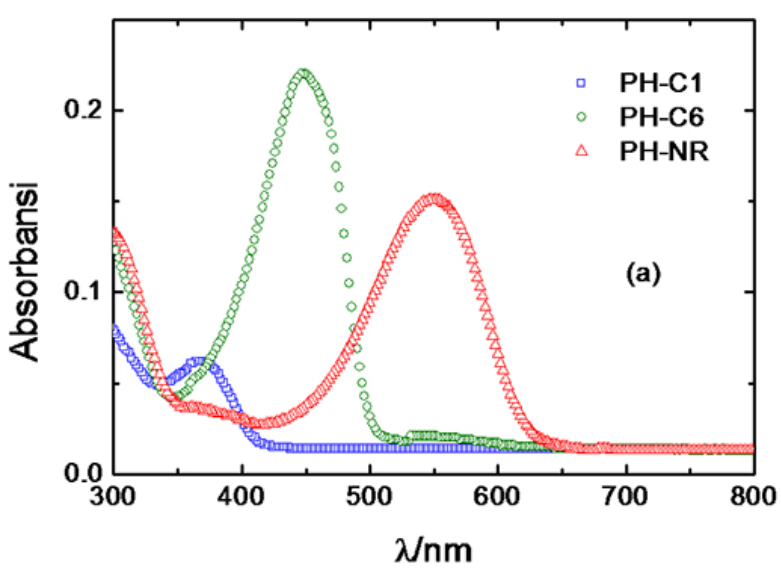

(a)

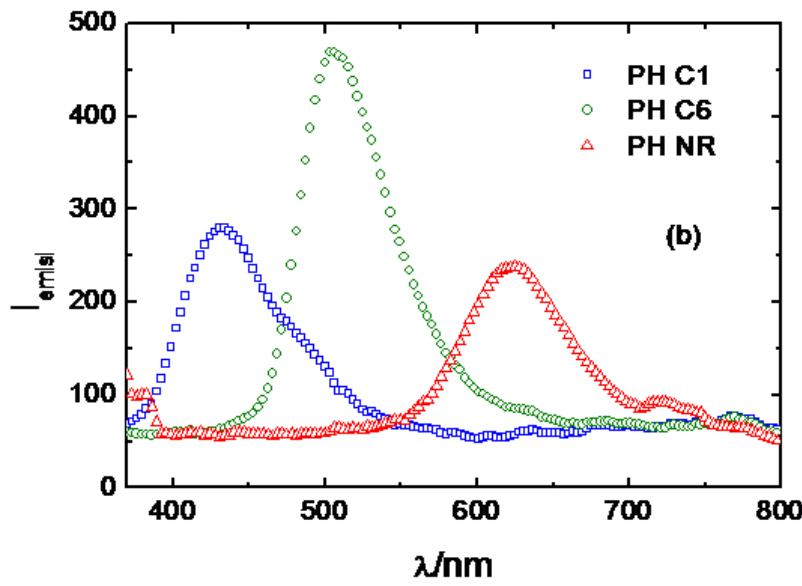

(b)

Gambar 1: Spektrum absorbsi (a) dan emisi (b) film polimer hibrid dengan doing kromofor emisi biru (film PHC1), emisi hijau (film PHC6), dan emisi merah (film PHNR).

rat terhadap massa prekursor. Selanjutnya, larutan tersebut dibuat menjadi lapisan tipis diatas substrat fused silica dengan teknik spincoating pada kecepatan $800 \mathrm{rpm}$.

Model divais fotoluminesen RGB multilapis dibuat lapis per lapis di atas substrat fused silica. Ada tiga macam konfigurasi model divais yang dibuat yaitu susunan lapisan $B / G / R$, $\mathrm{G} / \mathrm{R} / \mathrm{B}$, dan $\mathrm{R} / \mathrm{B} / \mathrm{G}$. Lapisan tipis yang didapat selanjutnya dikenakan proses pre-baked dalam oven dengan suhu $50 \mathrm{oC}$ selama 10 menit, untuk menghilangkan sisa pelarut. Selanjutnya, dilakukan proses fotopolimerisasi selama 4 menitdi dalam chamber yang dialiri gas nitrogen dengan menggunakan sumber sinar UV dari lampu Merkuri. Langkah selanjutnya adalah proses post-baked untuk menyempurnakan proses polimerisasi, yaitu dengan memanaskan sampel yang sudah difotopolimerisasi di dalam oven $50^{\circ} \mathrm{C}$ selam 6 jam. Tahapan pembuatan divais multilapis selanjutnya adalah pembuatan lapisan keduadan lapisan ketiga menggunakan prekursor polimer hibrid dengan warna lain. Tahap pelapisan tersebut sama seperti tahapan pembuatan lapisan pertama.

Karakterisasi yang dilakukan meliputi pengukuran spek- 
TABEL I: Karakteristik model divais fotoluminesen lapis tunggal yang dinyatakan dalam tinggi relatif puncak spektrum, $\lambda_{m a k s}$ absorpsi, $\lambda_{m a k s}$ emisi dan warna emisi.

\begin{tabular}{ccccc}
\hline \hline $\begin{array}{c}\text { Kode } \\
\text { Sampel }\end{array}$ & Kromofor & $\begin{array}{c}\lambda_{\text {maks }} \\
\text { Absorpsi }\end{array}$ & $\begin{array}{c}\lambda_{\text {maks }} \\
\text { Emisi }\end{array}$ & $\begin{array}{c}\text { Warna } \\
\text { Emisi }\end{array}$ \\
\hline PHC1 & Coumarine 1 & $366 \mathrm{~nm}$ & $431 \mathrm{~nm}$ & Biru \\
& & (rendah) & (sedang) & \\
PHC6 & Coumarine 6 6 & $\begin{array}{c}454 \mathrm{~nm} \\
\text { (tinggi) }\end{array}$ & $\begin{array}{c}504 \mathrm{~nm} \\
\text { (tinggi) }\end{array}$ & Hijau \\
PHNR & Nile Red & $\begin{array}{c}550 \mathrm{~nm} \\
\text { (sedang) }\end{array}$ & $\begin{array}{c}\text { (s) nm } \\
\text { (sedang) }\end{array}$ & Merah \\
& & &
\end{tabular}

trum absorpsi menggunakan Spectrometer UV-Vis Absorption, pengukuran spektrum emisi menggunakan modul Spectrometer Fluoresence USB4000, dan perekaman warna emisi menggunakan kamera 10 megapixel.

\section{HASIL DAN PEMBAHASAN}

Prekursor polimer hibrid yang dihasilkan berupa gel bening yang sangat kental. Polimer hibrid yang didoping dengan Coumarine-1 (PHC1) tampak bening, serupa dengan larutan Coumarine-1 dalam kloroform. Dalam bentuk film, PHC1 juga tampak bening dan mengeluarkan emisi berwarna biru jika dikenakan cahaya UV. Polimer hibrid yang didoping dengan Coumarine-6 (PHC6) berwarna hijau dan yang didoping dengan Nile-Red (PHNR) berwarna merah, serupa dengan warna larutan kromofor dalam bentuk larutan. Film PHC6 yang dihasilkan berwarna kuning kehijauan dan film PHNR berwarna merah. Masing-masing sampel tersebut mengeluarkan emisi berwarna hijau dan merah jika dikenakan cahaya UV.

Proses pembentukan model divais multi lapis ini sangat mudah dan sederhana, yaitu dengan teknik spincoating. Hal tersebut sangat berbeda dibanding proses pembuatan model divais dari bahan an-organik yang membutuhkan teknik deposisi vakum yang sangat mahal. Dengan demikian, hal tersebut memungkinkan untuk meminimalkan biaya produksi. Selain itu, teknik pelapisan tersebut memungkinkan untuk membuat model divais dengan ukuran besar.

Pada Gambar 1(a) dan 1(b) diperlihatkan pola spektrum absorbsi dan spektrum emisi dari model divais lapis tunggal untuk polimer hibrid yang didoping kromofor emisi biru (PHC1), kromofor emisi hijau (PHC6), dan kromofor emisi merah (PHNR). Karakteristik model divais lapis tunggal ini diperlihatkan dalam Tabel I. Masing-masing model devais tunggal tersebut memiliki $\lambda_{m a k s}$ absorbs dan emisi yang bersesuaian dengan $\lambda_{\text {maks }}$ warna kromofor. Dibandingkan dengan Coumarine 6 dan Nile Red, Coumarine 1 memiliki tinggi puncak spektrum yang relative rendah.

Seperti sudah dijelaskan sebelumnya, ada 3 macam konfigurasi model divais fotoluminisen RGB multilapis yang dibuat, masing-masing terdiri dari 3 lapisan berbeda di atas substrat fused silica, yaitu model $\mathrm{PH}(\mathrm{C} 1 / \mathrm{C} 6 / \mathrm{NR})$ dengan urutan lapisan $\mathrm{PHC} 1 / \mathrm{PHC} 6 / \mathrm{PHNR}$, model $\mathrm{PH}(\mathrm{C} 6 / \mathrm{NR} / \mathrm{C} 1)$ dengan urutan lapisan PHC6/PHNR/PHC1, dan model

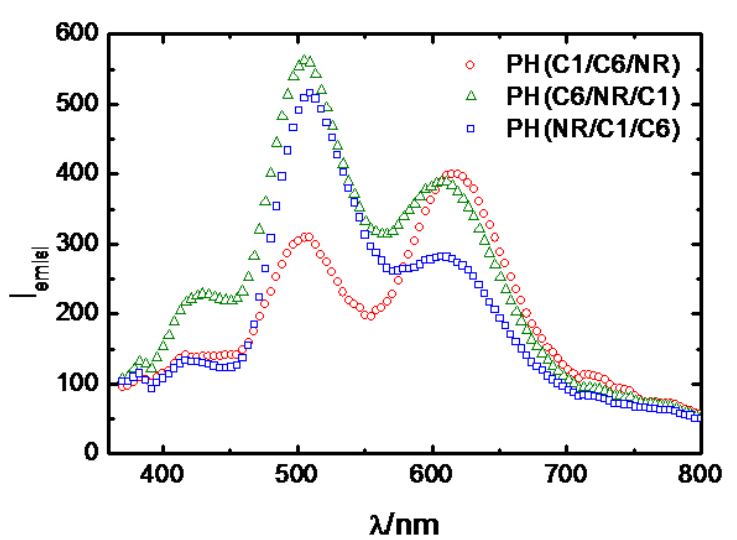

Gambar 2: Perbandingan spektrum emisi model divais fotoluminesen RGB mutilapis untukkonfigurasi $\mathrm{PH}(\mathrm{C} 1 / \mathrm{C} 6 / \mathrm{NR})$ (simbol O), konfigurasi $\mathrm{PH}(\mathrm{C} 6 / \mathrm{NR} / \mathrm{C} 1)(\Delta)$, dan konfigurasi $\mathrm{PH}(\mathrm{NR} / \mathrm{C} 1 / \mathrm{C} 6)$ ( $\square$ ).

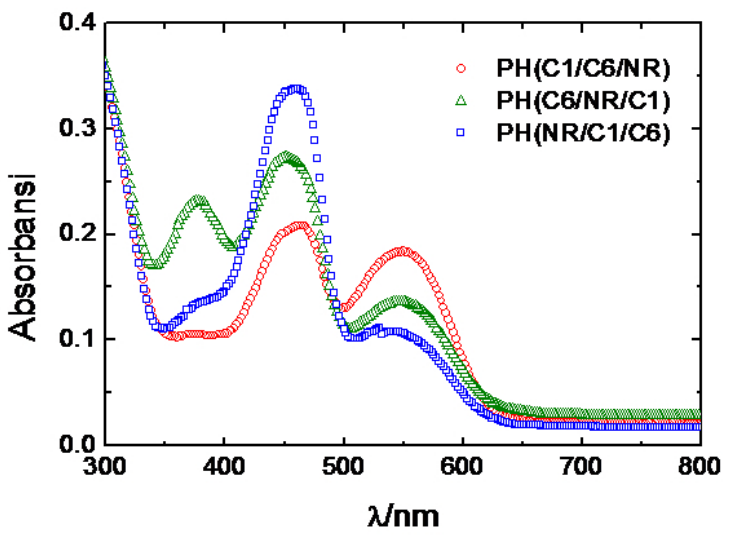

Gambar 3: Perbandingan spektrum absorbsi model divais fotoluminesen RGB mutilapis untukkonfigurasi $\mathrm{PH}(\mathrm{C} 1 / \mathrm{C} 6 / \mathrm{NR})$ (simbol O), konfigurasi $\mathrm{PH}(\mathrm{C} 6 / \mathrm{NR} / \mathrm{C} 1)(\Delta)$, dan konfigurasi $\mathrm{PH}(\mathrm{NR} / \mathrm{C} 1 / \mathrm{C} 6)$ $(\square)$.

PH(NR/C1/C6) denga urutan lapisan PHNR/PHC1/PHC6. Pada Gambar 2 diperlihatkan pola spektrum emisi dari ketiga model divais multilapis di atas. Ketiga model divais tersebut memiliki pola spektrum emisi kontinyu pada rentang panjang gelombang $400 \mathrm{~nm}$ sampai $800 \mathrm{~nm}$, dengan tiga puncak emisi pada panjang gelombang $\lambda_{1 E}=430 \mathrm{~nm}, \lambda_{2 E}=504$ $\mathrm{nm}$, dan $\lambda_{3 E}=624 \mathrm{~nm}$. Pola spektrum yang kontinyu hanya dalam rentang daerah visibel akan menjadikannya ramah pada kesehatan mata manusia. Pola tinggi komponen puncak emisi ketiga model divais mengalami perbedaan.Karakteristik perbandingan tinggi urutan komponen puncak emisi didapat melalui kuantisasi puncak spektrum masing-masing komponen warna diperlihatkan dalam Tabel II.

Pada model PH(C1/C6/NR), pola puncak menguat ke puncak ketiga menandakan terjadi proses absorpsi kuat oleh lapisan kedua dan ketiga sehingga emisi lapisan ketiga paling besar. Visual warna cahaya emisi divaisadalah kemerahan sesuai dengan warna lapisan terakhir yaitu Nile Red. Pada model $\mathrm{PH}(\mathrm{C} 6 / \mathrm{NR} / \mathrm{C} 1)$, pola puncak hampir simetris karena 
TABEL II: Perbandingan tinggi puncak emisi masing-masing komponen RGBpada ketiga konfigurasi model divais fotoluminesen RGB multilayer.

\begin{tabular}{cc}
\hline \hline $\begin{array}{c}\text { Konfigurasi } \\
\text { Divais }\end{array}$ & $\begin{array}{c}\text { Rasio Puncak Emisi } \\
\text { C1:C6:NR }\end{array}$ \\
\hline $\mathrm{PH}(\mathrm{C} 1 / \mathrm{C} 6 / \mathrm{NR})$ & $30: 70: 100$ \\
$\mathrm{PH}(\mathrm{C} 6 / \mathrm{NR} / \mathrm{C} 1)$ & $40: 100: 70$ \\
$\mathrm{PH}(\mathrm{NR} / \mathrm{C} 1 / \mathrm{C} 6)$ & $25: 100: 50$ \\
\hline \hline
\end{tabular}

TABEL III: Perbandingan tinggi puncak absorbsi masing-masing komponen RGBpada ketiga konfigurasi model divais fotoluminesen RGB multilayer.

\begin{tabular}{cc}
\hline \hline $\begin{array}{c}\text { Konfigurasi } \\
\text { Divais }\end{array}$ & $\begin{array}{c}\text { Rasio Puncak Emisi } \\
\text { C1:C6:NR }\end{array}$ \\
\hline $\mathrm{PH}(\mathrm{C} 1 / \mathrm{C} 6 / \mathrm{NR})$ & $50: 100: 85$ \\
$\mathrm{PH}(\mathrm{C} 6 / \mathrm{NR} / \mathrm{C} 1)$ & $85: 100: 50$ \\
$\mathrm{PH}(\mathrm{NR} / \mathrm{C} 1 / \mathrm{C} 6)$ & $35: 100: 35$ \\
\hline \hline
\end{tabular}

posisi lapisan pertama memiliki sifat absorpsi dan emisi kuat. Visual warna cahaya emisi divaisadalahmerah muda menuju putih.Selanjutnya, pada model $\mathrm{PH}(\mathrm{NR} / \mathrm{C} 1 / \mathrm{C} 6)$, pola puncak hampir simetris dengan puncak pertama lebih teredam karena diserap oleh lapisan ketiga yang memiliki sifat absorpsi dan emisi kuat. Visual warna cahaya emisi divaisadalahputih keabuan.

Secara keseluruhan, hasil ini menunjukkan divais model $\mathrm{PH}(\mathrm{C} 6 / \mathrm{NR} / \mathrm{C} 1)$ yang terdiri dari urutan lapisan film PHC6, filmPHNR, dan film PHC1 tidak dapat menghasilkan emisi putih. Perbandingan kromofor yang tepat memungkinkan diperoleh divais fotoluminisen dengan emisi mendekati cahaya putih.

Pada Gambar 3 diperlihatkan pola spektrum absorpsi dari ketiga model divais multilapis di atas. Ketiga model divais tersebut memiliki pola spektrum absorpsikontinyu pada rentang panjang gelombang $330 \mathrm{~nm}$ sampai $750 \mathrm{~nm}$, den- gan tigapuncak absorpsi pada panjang gelombang $\lambda_{1 A}=375$ $\mathrm{nm}, \lambda_{1 A}=450 \mathrm{~nm}$, dan $\lambda_{1 A}=550 \mathrm{~nm}$.Bila dikaitkan dengan pola letak puncak spektrum emisi biru yang berdekatan dengan puncak absorpsi hijau dan yang berikutnya maka kemungkinan besar telah terjadi mekanisme proses absorpsi-emisi diantara ketiga bahan kromofor.Karakteristik perbandingan tinggi urutan komponen puncak emisi yang didapat melalui kuantisasi puncak spektrum absorbsi masing-masing warna diperlihatkan dalam Tabel III.

Hasil uraian di atas menunjukkan model divais multi lapis dengan konfigurasi $\mathrm{PH}(\mathrm{C} 6 / \mathrm{NR} / \mathrm{C} 1)$ yang dibuat dari lapisan film PHC6, film PHNR, dan film PHC1 punya potensi untuk menghasilkan emisi menuju emisi cahaya putih, walaupun belum sempurna. Diperlukan optimasi lebih lanjut yang mencakup konsentrasi kromofor atau ketebalan lapisan untuk menghasilkan emisi putih sempurna.

\section{SIMPULAN}

Dalam eksperimen yang dilakukan telah dihasilkan model divais fotoluminesen RGB multilapis dengan tiga macam konfigurasi urutan susunan lapisan RGB, yaitu: model $\mathrm{PH}(\mathrm{C} 1 / \mathrm{C} 6 / \mathrm{NR})$, model $\mathrm{PH}(\mathrm{C} 6 / \mathrm{NR} / \mathrm{C} 1)$ dan model $\mathrm{PH}(\mathrm{NR} / \mathrm{C} 1 / \mathrm{C} 6)$. Dengan menggunakan karakteristik spektrum emisi dan warna emisi, telah didapat model divais multilapis konfigurasi model $\mathrm{PH}(\mathrm{C} 6 / \mathrm{NR} / \mathrm{C} 1)$ memiliki spektrum emisi kontinyu dalam rentang 400-700 nm yang mendekati emisi cahaya putih

\section{Ucapan Terima Kasih}

Penelitian yang dibiayai Proyek Hibah Penelitian DIPA Universitas Padjadjaran, Direktorat Jendral Pendidikan Tinggi, Departemen Pendidikan Nasional
[1] B.W. D'Andrade, S.R. Forrest,Adv. Matter. 16(18), 1585-1595 (2004).

[2] D.A. Steigerwald, et al., IEEE J. on Selected Topics in Quantum Electronics, 8(2), 310-320 (2002).

[3] H. Kudo, et al., Phys. Stat. Sol.(a), 200(1), 95-98 (2003).

[4] S. Guha, et al., J. Appl. Phys., 82(8), 4126-4128 (1997).
[5] F. Hide, et al., Appl. Phys. Lett., 70(20), 2664-2666 (1997).

[6] I. H. Raja, et al., Monatsh Chem, 139, 725-737 (2008).

[7] A. J. Steckl, J.M. Heikenfeld, S.C. Allen, IEEE/OSA J. of Display Technology, 1(1), 157-166 (2005). 